\title{
HUBUNGAN KUALITAS SANITASI RUMAH DENGAN KEJADIAN PENYAKIT INFEKSI SALURAN PERNAPASAN AKUT (ISPA) DI WILAYAH KERJA PUSKESMAS IV DENPASAR SELATAN KOTA DENPASAR
}

\author{
I Gede Sumertha Gapar ${ }^{1 *}$, Nyoman Adi Putra'), I.B.G. Pujaastawa ${ }^{3)}$ \\ ${ }^{1)}$ Badan Kepegawaian Daerah Provinsi Bali \\ 2) Fakultas Kedokteran Universitas Udayana \\ ${ }^{3)}$ Program Studi Magister (S2) Kajian Budaya Universitas Udayana \\ *Email : sumerthagaparigede@yahoo.co.id
}

\begin{abstract}
Besides positive results, the rapid development and growth of Denpasar City has also brought some problems to the Government of Denpasar City, for example the emergence of housing complexes that did not meet health standards and requirements. This problem can cause negative impacts toward the health condition of city residents, especially in the form of diseases influenced by environment factors such as acute respiratory infections (ARI). Based on that phenomena this study was carried out to examine the causal relationship between home sanitation factors (ventilation, natural lighting, humidity, temperature, population density, and air pollution) and the event of acute respiratory infections (ARI) in the working area of Public Health Centre IV of Denpasar Selatan District, in Denpasar City.

This study had an observational nature and employed a cross-sectional design. Based on data analysis applied, this study belong to analytical studies. Population size of this study was 5,777 and covered all inhabited houses in the working areas of Public Health Centre IV of Denpasar Selatan District. Sample of 97 houses were taken using proporsional stratified random sampling.

Statistical tests shows that: (1) the quality of house sanitation has a significance value $p=0.000$ ( $\operatorname{sig} p$ $<0.05)$, (2) house ventilation has a significance value $=0.162$ ( $\operatorname{sig} \mathrm{p}>0.05,(3)$ natural lighting has a significance value $\mathrm{p}=0.002$ ( $\operatorname{sig} \mathrm{p}<0.05$ ), (4) Room humidity has a significance value $\mathrm{p}=0.003$ ( $\operatorname{sig} \mathrm{p}<0.05)$, (5) Room temperature has a significance value $\mathrm{p}=0.491$ ( $\operatorname{sig} \mathrm{p}>0.05)$, (6) house population density has a significance value $\mathrm{p}=0.123(\operatorname{sig} \mathrm{p}>0.05)$, (7) Air population in the house has a significance value $\mathrm{p}=0.001(\operatorname{sig} \mathrm{p}<0.05)$.

Based on the results of our study it can be concluded that the quality of house sanitation affect the event of acute respiratory infections (ARI) diseases. The variables of house sanitation that affect the event of ARI diseases are: room humidity $(\mathrm{OR}=0.321)$, air population in the house $(\mathrm{OR}=0.233)$, natural lighting $(\mathrm{OR}=$ 0.151). Our study found that the probability of people who live in a house with below-standard-sanitationquality to be stricken by ARI diseases was $97.7 \%$.

Based on the results of our study it can be suggested that to the people that built the house of a qualified health.
\end{abstract}

Keywords: sanitation quality; house; disease; Acute respiratory Infections.

\section{PENDAHULUAN}

Program Pemberantasan Penyakit Infeksi Saluran Pernapasan Akut (ISPA) di Indonesia sudah dimulai pada tahun 1984, tetapi sampai saat ini penyakit ISPA masih menjadi masalah kesehatan masyarakat termasuk di Provinsi Bali. Ini ditunjukkan dengan pola 10 penyakit terbanyak pada pasien di Puskesmas dari tahun 2011 sampai dengan tahun 2013 menunjukkan kasus yang menduduki urutan pertama adalah infeksi akut lain pada saluran napas bagian atas. Kasus terbanyak ditemukan di Kota Denpasar. Di sisi lain, berdasarkan Laporan Data Kesakitan Puskesmas Kota Denpasar Tahun 2013 menunjukkan bahwa penyakit ISPA menduduki peringkat pertama dari 11 penyakit terbanyak di Puskesmas. Terbanyak ditemukan di Kecamatan Denpasar Selatan, khususnya di wilayah kerja Puskesmas IV Denpasar Selatan (Dinas
Kesehatan Kota Denpasar, 2014). Berdasarkan observasi awal yang dilakukan di wilayah ini, banyak dijumpai permukiman penduduk yang sangat padat serta kurang tertata dan saling berhimpitan antara rumah yang satu dengan lainnya. Keadaan ini tentunya sangat berpengaruh terhadap kualitas sanitasi rumah di wilayah tersebut, seperti : sirkulasi udara dalam rumah menjadi terganggu, pencahayaan alami rumah juga terganggu (sinar matahari terhalang masuk ke dalam rumah), serta kelembaban udara dalam rumah menjadi tinggi. Hal ini dipandang penting dan menarik untuk dikaji sebagai upaya untuk mengetahui hubungan kualitas sanitasi rumah dengan kejadian penyakit ISPA di wilayah kerja Puskesmas IV Denpasar Selatan Kota Denpasar. Permasalahan di atas akan dicoba dipahami dengan menjawab pertanyaan-pertanyaan yang diformulasikan sebagai berikut : bagaimanakah hubungan kualitas sanitasi rumah dengan 
kejadian penyakit ISPA di wilayah kerja Puskesmas IV Denpasar Selatan? dan seberapa jauh hubungan variabel kualitas sanitasi rumah yang meliputi ventilasi, suhu, kelembaban, pencahayaan alami, kepadatan hunian, dan pencemaran udara dalam rumah dengan kejadian penyakit ISPA di wilayah kerja Puskesmas IV Denpasar Selatan?

\section{METODE PENELITIAN}

Berdasarkan jenisnya penelitian ini adalah penelitian observasional. Berdasarkan waktu penelitian, rancang bangun penelitian ini adalah penelitian cross sectional. Sedangkan berdasarkan analisis data, penelitian ini merupakan penelitian analitik. Populasi dalam penelitian ini adalah seluruh rumah yang dihuni oleh Kepala Keluarga yang berdomisili di wilayah kerja Puskesmas IV Denpasar Selatan sebanyak 5.777 rumah dengan sampel sebanyak 97 rumah. Pengambilan sampel menggunakan teknik proporsional stratified random sampling. Pengumpulan data dilakukan dengan wawancara, observasi dan pengukuran. Analisis data meliputi (Dahlan, 2010) : analisis univariat, analisis bivariat, serta analisis multivariat dengan menggunakan analisis regresi logistik (Yasril dan Kasjono, 2009).

\section{HASIL DAN PEMBAHASAN}

\subsection{Karakteristik Responden}

Jumlah responden yang digunakan sebanyak 97 responden yang tersebar di 14 banjar pada wilayah kerja Puskesmas IV Denpasar Selatan. Tabel 1 menunjukkan data distribusi responden.

Tabel 1. Distribusi Karakteristik Responden

\begin{tabular}{|c|c|c|c|}
\hline $\begin{array}{l}\text { Identitas } \\
\text { Responden }\end{array}$ & $\begin{array}{l}\text { Distribusi } \\
\text { Responden }\end{array}$ & h Orang & Persentase \\
\hline \multirow[t]{3}{*}{ Jenis Kelamin } & Laki-laki & 26 & 26,8 \\
\hline & Perempuan & 71 & 73,2 \\
\hline & Jumlah & 97 & $100 \%$ \\
\hline \multirow[t]{7}{*}{ Kelompok Umur } & d"20 tahun & 4 & 4,12 \\
\hline & 21-30 tahun & 10 & 10,31 \\
\hline & 31-40 tahun & 31 & 31,96 \\
\hline & 41-50 tahun & 33 & 34,02 \\
\hline & $51-60$ tahun & 10 & 10,31 \\
\hline & e"61 tahun & 9 & 9,28 \\
\hline & Jumlah & 97 & 100 \\
\hline \multirow[t]{6}{*}{ Tingkat Pendidikan } & $\begin{array}{l}\text { Tidak sekolah/ } \\
\text { tidak tamat SD }\end{array}$ & 7 & 7,2 \\
\hline & Tamat SD & 13 & 13,4 \\
\hline & Tamat SLTP & 19 & 19,6 \\
\hline & Tamat SLTA & 53 & 54,6 \\
\hline & $\begin{array}{l}\text { Tamat Perguruan Tinggi/ } \\
\text { Akademi }\end{array}$ & 5 & 5,2 \\
\hline & Jumlah & 97 & 100 \\
\hline
\end{tabular}

\subsection{Kejadian Penyakit ISPA}

Distribusi kejadian ISPA di Wilayah Kerja Puskesmas IV Denpasar Selatan dapat dilihat pada Tabel 2.

Tabel 2. Distribusi Kejadian ISPA di Wilayah Kerja Puskesmas IV Denpasar Selatan

\begin{tabular}{llcc}
\hline No. & Kejadian ISPA & Jumlah & Prosentase $(\%)$ \\
\hline 1. & Tidak Sakit ISPA & 31 & 32 \\
2. & Sakit ISPA & 66 & 68 \\
\hline & Total & 97 & 100 \\
\hline
\end{tabular}

\subsection{Hubungan Kualitas Sanitasi Rumah dengan Kejadian Penyakit ISPA}

Hubungan kualitas sanitasi rumah dengan kejadian ISPA dapat dilihat pada Tabel 3 berikut :

Tabel 3. Tabulasi Silang Antara Kualitas Sanitasi Rumah dengan Kejadian ISPA di Wilayah Kerja Puskesmas IV Denpasar Selatan

\begin{tabular}{|c|c|c|c|c|c|c|c|}
\hline \multirow[t]{3}{*}{ No. } & \multirow{3}{*}{$\begin{array}{l}\text { Kualitas Sanitasi } \\
\text { Rumah }\end{array}$} & \multicolumn{4}{|c|}{ Kejadian ISPA } & \multicolumn{2}{|c|}{ Total } \\
\hline & & \multicolumn{2}{|c|}{ Sakit ISPA } & \multicolumn{2}{|c|}{ Tidak Sakit ISPA } & \multirow[b]{2}{*}{ Jml. } & \multirow[b]{2}{*}{$\%$} \\
\hline & & Jml. & $\%$ & Jml. & $\%$ & & \\
\hline 1. & Baik & 23 & 45,1 & 28 & 54,9 & 51 & 52,6 \\
\hline 2. & Cukup & 26 & 89,7 & 3 & 10,3 & 29 & 29,9 \\
\hline 3. & Kurang & 17 & 100 & 0 & 0 & 17 & 17,5 \\
\hline & Total & 66 & 68 & 31 & 32 & 97 & 100 \\
\hline
\end{tabular}

Keterangan : sig $p=0,000$

Dari uji statistik didapatkan bahwa kejadian ISPA di wilayah kerja Puskesmas IV Denpasar Selatan yang tinggal pada rumah dengan kualitas sanitasi kurang sebanyak 17 dari 17 orang (100\%), rumah dengan kualitas sanitasi cukup sebanyak 26 dari 29 orang $(89,7 \%)$ menderita ISPA, dan rumah dengan kualitas sanitasi baik sebanyak 23 dari 51 orang $(45,1 \%)$ menderita ISPA. Berdasarkan hasil uji chi square diperoleh nilai $p=0,000(p<0,05)$. Berarti ada hubungan antara kualitas sanitasi rumah dengan kejadian penyakit ISPA di wilayah kerja Puskesmas IV Denpasar Selatan. Hasil penelitian ini sesuai dengan WHO (2007) yang menyatakan bahwa penyebaran dan dampak penyakit ISPA berkaitan dengan empat hal. Salah satunya adalah kondisi lingkungan seperti kualitas sanitasi rumah, yaitu : polusi udara, kepadatan hunian, kelembaban, kebersihan, musim, suhu/ temperatur, ventilasi, dan penerangan alami rumah). Hal ini juga sesuai dengan hasil penelitian Ahmad dan Sulistyorini (2005) yang menyatakan sanitasi rumah mempunyai nilai sig $p=0,000(p<0,05)$. 
3.4. Hubungan Variabel Kualitas Sanitasi Rumah dengan Kejadian Penyakit ISPA

Distribusi kejadian penyakit ISPA pada masingmasing variabel kualitas sanitasi rumah dapat dilihat pada Tabel 4 . dikatakan bahwa rumah yang memiliki penerangan alami yang tidak memenuhi syarat di wilayah kerja Puskesmas IV Denpasar Selatan Kota Denpasar mempunyai kemungkinan 8,286 kali untuk terjadinya penyakit ISPA dibandingkan dengan yang

Tabel 4. Tabulasi Silang Antara Variabel Kualitas Sanitasi Rumah dengan Kejadian Penyakit ISPA di Wilayah Kerja Puskesmas IV Denpasar Selatan

\begin{tabular}{|c|c|c|c|c|c|c|c|c|c|}
\hline \multirow{3}{*}{ No. } & \multirow{3}{*}{ Variabel } & \multirow{3}{*}{ Kondisi } & \multicolumn{4}{|c|}{ Kejadian ISPA } & \multirow{3}{*}{ Jumlah } & \multirow{3}{*}{$\operatorname{sig} p$} & \multirow{3}{*}{ OR } \\
\hline & & & \multicolumn{2}{|c|}{ Sakit ISPA } & \multicolumn{2}{|c|}{ Tidak Sakit ISPA } & & & \\
\hline & & & Jml. & $\%$ & $\mathrm{Jml}$ & $\%$ & & & \\
\hline \multirow[t]{2}{*}{1.} & Ventilasi Rumah & Tdk memenuhi syarat & 4 & 100 & 0 & 0 & 4 & 0,162 & \\
\hline & & Memenuhi syarat & 62 & 66,7 & 31 & 33,3 & 93 & & \\
\hline \multirow[t]{2}{*}{2.} & Penerangan Alami & Tdk memenuhi syarat & 24 & 92,3 & 2 & 7,7 & 26 & 0,002 & 8,286 \\
\hline & Ruang Rumah & Memenuhi syarat & 42 & 59,2 & 29 & 40,8 & 71 & & \\
\hline \multirow[t]{2}{*}{3.} & Kelembaban & Tdk memenuhi syarat & 36 & 83,7 & 7 & 16,3 & 43 & 0,003 & 4,114 \\
\hline & Ruang Rumah & Memenuhi syarat & 30 & 55,6 & 24 & 44,4 & 54 & & \\
\hline \multirow[t]{2}{*}{4.} & Suhu Ruang & Tdk memenuhi syarat & 1 & 100 & 0 & 0 & 1 & 0,491 & \\
\hline & Rumah & Memenuhi syarat & 65 & 67,7 & 31 & 32,3 & 96 & & \\
\hline \multirow[t]{2}{*}{5.} & Kepadatan Hunian & Padat & 15 & 83,3 & 3 & 16,7 & 18 & 0,123 & \\
\hline & Ruang Tidur & Tidak padat & 51 & 64,6 & 28 & 35,4 & 79 & & \\
\hline \multirow[t]{2}{*}{6.} & Pencemaran Udara & Ada pencemaran & 43 & 82,7 & 9 & 17,3 & 52 & 0,001 & 4,570 \\
\hline & Dalam Rumah & Tidak ada pencemaran & 23 & 51,1 & 22 & 48,9 & 45 & & \\
\hline
\end{tabular}

Dari hasil uji statistik didapatkan bahwa kejadian ISPA di wilayah kerja Puskesmas IV Denpasar Selatan yang tinggal pada rumah dengan ventilasi tidak memenuhi syarat sebanyak 4 dari 4 orang (100\%). Sedangkan yang tinggal pada rumah dengan ventilasi yang memenuhi syarat yaitu sebanyak 62 dari 93 orang $(66,7 \%)$ menderita ISPA. Berdasarkan hasil uji chi square diperoleh nilai $p=0,162(p>0,05)$. Dengan demikian ventilasi tidak merupakan faktor risiko untuk terjadinya penyakit ISPA di wilayah kerja Puskesmas IV Denpasar Selatan Kota Denpasar.

Hasil penelitian ini berbeda dengan penelitian yang dilakukan oleh Oktaviani et al. (2010) yang menyatakan bahwa ventilasi mempunyai nilai sig $\mathrm{p}$ $=0,009(p<0,05)$. Begitu pula dengan hasil penelitian dari Yudarmawan (2012) yang menyatakan bahwa ventilasi mempunyai nilai sig $p=0,003(p<0,05)$, serta penelitian dari Fillacano (2013) yang menyatakan bahwa ventilasi mempunyai nilai sig $p=0,019$ $(\mathrm{p}<0,05)$.

Kejadian sakit ISPA di wilayah kerja Puskesmas IV Denpasar Selatan yang menempati rumah dengan penerangan alami tidak memenuhi syarat sebanyak 24 dari 26 orang $(92,3 \%)$, sedangkan yang menempati ruang tidur dengan penerangan alami yang memenuhi syarat yaitu sebanyak 42 dari 71 orang $(59,2 \%)$ menderita ISPA. Berdasarkan hasil uji chi square diperoleh nilai $\mathrm{p}=0,002(\mathrm{p}<0,05)$. Berarti ada hubungan penerangan alami rumah dengan kejadian penyakit ISPA di wilayah kerja Puskesmas IV Denpasar Selatan. Penerangan alami rumah memperoleh nilai $\mathrm{OR}=8,286$, sehingga dapat memiliki penerangan alami yang memenuhi syarat. Hasil penelitian ini sesuai dengan penelitian Ahmad dan Sulistyorini (2005), menyatakan bahwa penerangan alami memperoleh nilai $\mathrm{p}=0,047$ $(\mathrm{p}<0,05)$, seta penelitian Suryani et al. (2015) bahwa penerangan alami memperoleh nilai $\mathrm{p}=0,001$ $(p<0,05)$. Hasil yang berbeda justru diperoleh dari penelitian Yudarmawan (2012) yang menunjukkan bahwa penerangan alami mempunyai nilai sig $p=0,093$ berada diatas nilai sig $p=0,05$ serta penelitian yang dilakukan Maryani (2012) diperoleh nilai sig $\mathrm{p}$ $=0,937(\mathrm{p}>0,05)$.

Melihat bahwa penerangan alami rumah merupakan faktor risiko untuk terjadinya penyakit ISPA di wilayah kerja Puskesmas IV Denpasar Selatan Kota Denpasar, maka diperlukan adanya pembinaan dan penyuluhan tentang pentingnya pencahayaan alami rumah. Pencahayaan dalam ruang rumah diusahakan agar sesuai dengankebutuhan untuk melihat benda sekitar dan membaca berdasarkanpersyaratan minimal $60 \mathrm{Lux}$ (Kemenkes RI, 2011).

Kejadian penyakit ISPA pada orang yang menempati ruang rumah dengan kelembaban yang tidak memenuhi syarat sebanyak 36 dari 43 orang $(83,7 \%)$, sedangkan yang menempati ruang rumah dengan kelembaban yang memenuhi syarat sebanyak 30 dari 54 orang $(55,6 \%)$ menderita ISPA. Berdasarkan hasil uji chi square diperoleh nilai $\mathrm{p}=$ $0,003(p<0,05)$. Berarti ada hubungan kelembaban ruang rumah dengan kejadian penyakit ISPA di wilayah kerja Puskesmas IV Denpasar Selatan. Kelembaban ruang rumah memperoleh nilai $\mathrm{OR}=$ 
4,114, sehingga dapat dikatakan bahwa rumah yang memiliki kelembaban ruang yang tidak memenuhi syarat di wilayah kerja Puskesmas IV Denpasar Selatan Kota Denpasar mempunyai kemungkinan 4,114 kali untuk terjadinya penyakit ISPA dibandingkan dengan yang memiliki kelembaban ruang yang memenuhi syarat. Hal ini sesuai dengan hasil penelitian Maryani (2012), bahwa kelembaban kamar memperoleh nilai sig $p=0,000(p<0,05)$. Hasil yang sesuai juga diperoleh dari penelitian Hasil penelitian Nindya dan Sulistyorini (2005), bahwa kelembaban ruangan berpengaruh terhadap ISPA pada balita.

Hasil berbeda diperoleh dari penelitian Ahmad dan Sulistyorini (2005), diperoleh nilai $\mathrm{p}=0,134$ ( $p>0,05)$ untuk kelembaban alami rumah.

Kejadian sakit ISPA pada orang yang menempati ruang rumah dengan suhu yang tidak memenuhi syarat sebanyak 1 dari 1 orang (100\%), sedangkan yang menempati ruang rumah dengan suhu yang memenuhi syarat yaitu sebanyak 65 dari 96 orang $(67,7 \%)$ menderita ISPA. Berdasarkan hasil uji chi square diperoleh nilai sig $p=0,491(p>0,05)$. Berarti tidak ada hubungan suhu ruang rumah dengan kejadian penyakit ISPA di wilayah kerja Puskesmas IV Denpasar Selatan. Dengan demikian suhu ruang rumah bukan merupakan faktor risiko untuk terjadinya penyakit ISPA di wilayah kerja Puskesmas IV Denpasar Selatan Kota Denpasar. Hasil yang sama diperoleh dari penelitian Ahmad dan Sulistyorini (2005), diperoleh nilai $\mathrm{p}=0,179$ $(p>0,05)$, serta penelitian Yudarmawan (2012) diperoleh nilai $p=0,198(p>0,05)$.

Kejadian sakit ISPA pada orang menempati ruang tidur dengan kepadatan hunian yang padat sebanyak 15 dari 18 orang (83,3\%), sedangkan yang menempati ruang tidur dengan kepadatan hunian yang tidak padat yaitu sebanyak 51 dari 79 orang (64,6\%) menderita ISPA. Berdasarkan hasil uji chi square diperoleh nilai sig $\mathrm{p}=0,123(\mathrm{p}>0,05)$. Berarti tidak ada hubungan kepadatan hunian ruang tidur dengan kejadian penyakit ISPA di wilayah kerja Puskesmas IV Denpasar Selatan. Dengan demikian kepadatan hunian ruang tidur bukan merupakan faktor risiko untuk terjadinya penyakit ISPA di wilayah kerja Puskesmas IV Denpasar Selatan Kota Denpasar.

Hasil penelitian ini sesuai dengan penelitian Yudarmawan (2012) bahwa kepadatan hunian mempunyai nilai sig $\mathrm{p}=0,454$ berada diatas nilai sig $\mathrm{p}=0,05$. Hasil berbeda justru terlihat dari hasil penelitian Maryani (2012) didapat nilai p value $(0,000)$ kurang dari 0,05.

Kejadian sakit ISPA pada orang yang menempati ruang rumah dengan pencemaran udara yang tercemar sebanyak 43 dari 52 orang (82,7\%), sedangkan yang menempati ruang rumah dengan pencemaran udara yang tidak tercemar yaitu sebanyak 23 dari 45 orang $(51,1 \%$.) menderita ISPA.
Berdasarkan hasil uji chi square diperoleh nilai $\mathrm{p}=$ $0,001(\mathrm{p}<0,05)$. Berarti ada hubungan pencemaran udara dalam rumah dengan kejadian penyakit ISPA di wilayah kerja Puskesmas IV Denpasar Selatan. Dengan demikian pencemaran udara dalam rumah merupakan faktor risiko untuk terjadinya penyakit ISPA di wilayah kerja Puskesmas IV Denpasar Selatan Kota Denpasar. Pencemaran udara dalam rumah memperoleh nilai $\mathrm{OR}=4,570$, sehingga dapat dikatakan bahwa rumah yang memiliki kelembaban ruang yang tidak memenuhi syarat di wilayah kerja Puskesmas IV Denpasar Selatan Kota Denpasar mempunyai kemungkinan 4,570 kali untuk terjadinya penyakit ISPA dibandingkan dengan yang memiliki kelembaban ruang yang memenuhi syarat. Hasil penelitian ini sesuai dengan penelitian Sukarlan (2003), menunjukkan bahwa bahan pencemar berpengaruh secara signifikan terhadap kejadian ISPA pada Balita. Disebutkan bahwa odds ratio dari masing-masing bahan pencemar tersebut adalah sebesar 6,21 untuk obat nyamuk bakar, 3,04 untuk bahan bakar kayu dan 5,69 untuk asap rokok. Demikia pula halnya dengan hasil penelitian Nasution et al. (2009) serta Winarni et al. (2010), didapatkan hubungan yang bermakna antara pajanan asap rokok dengan kejadian ISPA pada Balita.

\subsection{Variabel Kualitas Sanitasi Rumah yang Berhubungan dengan Kejadian Penyakit ISPA}

Melalui analisis multivariat dengan menggunakan analisis regresi logistik diperoleh variabel yang berhubungan dengan kejadian penyakit ISPA, yaitu : kelembaban ruang rumah $(\mathrm{OR}=0,321)$, Pencemaran udara dalam rumah $(\mathrm{OR}=0,233)$, dan penerangan alami rumah $(\mathrm{OR}=0,151)$, sedangkan probabilitas orang yang menempati rumah dengan kualitas sanitasi (penerangan alami, kelembaban, dan pencemaran udara dalam rumah) yang tidak memenuhi syarat di wilayah kerja Puskesmas IV Denpasar Selatan untuk terkena ISPA adalah 97,7\%.

\section{SIMPULAN DAN SARAN}

\subsection{Simpulan}

1. Terdapat hubungan antara kualitas sanitasi rumah dengan kejadian penyakit ISPA di wilayah kerja Puskesmas IV Denpasar Selatan.

2. Variabel kualitas sanitasi rumah yang berhubungan dengan kejadian penyakit ISPA, yaitu : kelembaban ruang rumah, pencemaran udara dalam rumah, dan penerangan alami rumah.

3. Probabilitas orang yang menempati rumah dengan kualitas sanitasi (penerangan alami, kelembaban, dan pencemaran udara dalam rumah) yang tidak memenuhi syarat di wilayah 
kerja Puskesmas IV Denpasar Selatan untuk terkena ISPA adalah 97,7\%.

\subsection{Saran}

Saran yang dapat penulis sampaikan, yaitu : kepada masyarakat di wilayah kerja Puskesmas IV Denpasar Selatan untuk selalu memperhatikan kualitas sanitasi rumahnya dengan cara menjaga atau membangun rumah sesuai dengan persyaratan kesehatan, terutama dengan memperhatikan faktorfaktor sanitasi rumah seperti : pencahayaan alami rumah, kelembaban rumah, dan pengendalian pencemaran udara dalam rumah.

\section{DAFTAR PUSTAKA}

Ahmad, Y.N., dan Lilis Sulistyorini. 2005. Hubungan Sanitasi Rumah Secara Fisik Dengan Kejadian ISPA Pada Balita. Jurnal Kesehatan Lingkungan 1 (2) : 110-119.

Dahlan, S. 2010. Statistik Untuk Kedokteran dan Kesehatan. Edisi 5. Jakarta: Salemba Medika..

Dinas Kesehatan Kota Denpasar, 2014. Laporan Data Kesakitan Puskesmas Kota Denpasar Tahun 2013. Denpasar : Dinas Kesehatan Kota Denpasar.

Fillacano, R. 2013. Hubungan Lingkungan Dalam Rumah Terhadap ISPA Pada Balita di Kelurahan Ciputat Kota Tangerang Selatan Tahun 2013. Skripsi. Jakarta : UIN Syarif Hidayatullah.

Kemenkes RI. 2011. Peraturan Menteri Kesehatan RI Nomor 1077/Menkes/Per/V/2011 tentang Pedoman Penyehatan Udara Dalam Ruang Rumah. Jakarta : Kemenkes RI.

Maryani, R.D., 2012. Hubungan Antara Kondisi Lingkungan Rumah dan Kebiasaan Merokok Anggota Keluarga Dengan Kejadian ISPA Pada Balita Di Kelurahan Bandarharjo Kota Semarang. Skripsi. Semarang : Universitas Negeri Semarang.

Nasution K., M. Azharry Rully Sjahrullah, Kartika Erida Brohet, Krishna Adi Wibisana, M. Ramdhani Yassien, Lenora Mohd. Ishak, Liza Pratiwi, Corrie Wawolumaja, dan Bernie
Endyarni. 2009. Infeksi Saluran Nafas Akut pada Balita Di Daerah Urban Jakarta. Jurnal Sari Pediatri 11 (4) : 223-228.

Nindya T.S., dan Lilis Sulistyorini. 2005. Hubungan Sanitasi Rumah Dengan Kejadian Infeksi Saluran Pernafasan Akut (ISPA) Pada Balita. Jurnal Kesehatan Lingkungan 2 (1) : 43-52.

Oktaviani D., Nur Alam Fajar, dan Imelda G Purba. 2010. Hubungan Kondisi Fisik Rumah dan Perilaku Keluarga Terhdap Kejadian ISPA Pada Balita Di Kelurahan Cambai Kota Prabumulih tahun 2010. Jurnal Pembangunan Manusia 4 (10) : 1-15.

Sukarlan, 2003. Faktor Risiko Kejadian Pnemonia pada Balita di Rumah Sakit Umum Ulin di Kota Banjarmasin. Tesis : Universitas Airlangga.

Suryani I., Edison, dan Julizar Nazar. 2015. Hubungan Lingkungan Fisik dan Tindakan Penduduk dengan Kejadian ISPA pada Balita di Wilayah Kerja Puskesmas Lubuk Buaya. Jurnal Kesehatan Andalas 4 (1) : 157-167.

WHO. 2007. Pencegahan dan Pengendalian Infeksi Saluran Pernafasan Akut (ISPA) Yang Cenderung Menjadi Epidemi dan Pandemi di Fasilitas Pelayanan Kesehatan. Jakarta : Trust Indonesia

Winarni, Basirun Al Ummah, dan Safrudin Agus Nur Salim. 2010. Hubungan Antara Perilaku Merokok Orang Tua dan Anggota Keluarga Yang Tinggal Dalam Satu Rumah Dengan Kejadian ISPA Pada Balita Di Wilayah Kerja Puskesmas Sempor II Kabupaten Kebumen Tahun 2009. Jurnal Ilmiah Kesehatan Keperawatan 6 (1) : 16-20.

Yasril, dan Heru Subaris Kasjono. 2009. Analisis Multivariat Untuk Penelitian Kesehatan. Cetakan pertama. Jogjakarta : Mitra Cendekia Press.

Yudarmawan, I N. 2012. Pengaruh Faktor-Faktor Sanitasi Rumah Terhadap Kejadian Penyakit ISPA Pada Anak Balita (Study Dilakukan pada Masyarakat di Desa Dangin Puri Kangin Kecamatan Denpasar Utara Kota Denpasar Tahun 2012). Skripsi. Denpasar : Poltekkes Denpasar. 